\title{
MỨC Độ TUÂN THỦ SỬ DỤNG VỚ Y KHOA Ở NGƯờI BỆNH SUY TĨNH MẠCH CHI DƯỚI MẠN TÍNH
}

\section{TÓM TÁT}

Trong thời gian từ tháng 5 đến tháng 6 năm 2020, có 88 người bệnh suy tĩnh mạch chi dưới mạn tính có chỉ định mang vớ y khoa để điều trị suy tĩnh mạch tại phòng khám Lồng ngực - Mạch máu bệnh viện Đại Học Y Dược Tp. Hồ Chí Minh. Tỷ lệ nữ chiếm 89,8\%, tuồi trung bình 54 . Phân loại lâm sàng CEAP nhóm $\mathrm{C} 0-\mathrm{C} 1$ chiếm $58 \%$ so với các nhóm còn lại. Kết quả có 40,9\% người bệnh suy TMCDMT tuân thủ sử dụng vớ $\mathrm{y}$ khoa theo chỉ định. Yếu tố về trình độ văn hóa và phân loại lâm sàng CEAP của người bệnh có liên quan đến mức độ tuân thủ sử dụng vớ y khoa.

Từ khóa: Suy tĩnh mạch, vớ y khoa, tuân thủ.

\section{SUMMARY \\ LEVEL OF ADHERENCE OF COMPRESSION STOCKINGS IN PATIENTS WITH CHRONIC VENOUS INSUFFICIENCY}

During the period from May to June 2020, there were 88 patients with chronic venous insufficiency appointed to wear compression stockings to treat varicose veins at the Thoracic Vascular clinic of the University of Medicine and Pharmacy HCMC. The percentage of women accounted for $89.8 \%$, the average age of 54 . Clinical classification CEAP group $\mathrm{C} 0-\mathrm{Cl}$ accounted for $58 \%$ compared to the remaining groups. As a result, $40.9 \%$ of patients with CVI use compression stockings as directed. Patient education and CEAP clinical determinants are related to the level of adherence of compression stockings.

Key words: Chronic venous insufficiency, compression stockings, adherence.

\section{I. ĐẶT VẤN ĐỀ}

Suy tĩnh mạch chi dưới mạn tính (TMCDMT)
Võ Lệ Thu *, Nguyễn Hoài Nam **

là bệnh rất thường gặp và liên quan mật thiết đến lối sống. Bệnh tiến triển chậm, không rầm rộ, hầu như không gây tử vong ngoại trừ khi có biến chứng. Tuy nhiên, nếu không được phát hiện, điều trị kịp thời và đúng phương pháp thì bệnh sẽ càng ngày càng nặng hơn, ảnh hưởng đến sinh hoạt, công việc, chất lượng cuộc sống và tăng gánh nặng cho ngành y tế. Theo thống kê tại Hoa Kỳ, tỉ lệ mắc bệnh với chi phí chăm sóc y tế lên đến 3 tỷ đô la mỗi năm ${ }^{\text {[2], [5], [8] }}$.

Tại Việt Nam, trên thực tế bệnh cũng rất thường gặp, nhưng chưa thực sự có được sự chú ý của cả thầy thuốc và người bệnh. Theo báo cáo nghiên cứu Vein Consult Program - Vietnam 2011 cho thấy có đến $62 \%$ người bệnh không biết mình bị bệnh suy TMCDMT cho đến khi được thăm khám; theo thống kê đa trung tâm từ Đại Học Y Dược TP. Hồ Chí Minh thực hiện thì có tới 77,5\% bệnh nhân không hề biết về bệnh cho tới khi được chẩn đoán, trong đó $91,3 \%$ trường hợp không được điều trị, $8,7 \%$ được điều trị không đúng cách như dùng Aspirin, thuốc lợi tiểu hoặc các loại thuốc Đông ${ }^{[7]}$.

Mục tiêu chính của điều trị suy TMCDMT là giảm các triệu chứng và cải thiện chất lượng cuộc sống của người bệnh. Việc điều trị có thể là điều trị bảo tồn hay can thiệp ngoại khoa và hiệu quả tùy thuộc vào mức độ của bệnh. Trong điều trị bảo tồn thì việc sử dụng vớ y khoa là liệu pháp đầu tiên, lâu dài và liệu pháp này cũng được phối hợp sau can thiệp ngoại khoa cho người bệnh suy TMCDMT ${ }^{[19]}$.

\footnotetext{
* Bệnh viện Quốc tế Minh Anh

** Bộ môn Ngoại lồng ngục-Tim mạch, ĐHYD TP.HCM Ngườ chịu trách nhiệm khoa học: Võ Lệ Thu Ngày nhận bài: 02/08/2020 - Ngày Cho Phép Đăng: 04/09/2020

Phản Biện Khoa học: PGS.TS. Đặng Ngọc Hùng PGS.TS. Đoàn Quốc Hung
} 
Vớ y khoa dễ sử dụng, không xâm lấn, an toàn, hiệu quả trong việc kiểm soát tăng áp huyết áp tĩnh mạch - cơ chế sinh lý bệnh chính của suy TMCDMT làm tăng tuần hoàn máu theo chiều bình thường, tránh sự hình thành của các cục máu đông và giảm hiện tượng chân bị sưng phù. Mặc dù thấy được hiệu quả cao trong cải thiện triệu chứng lâm sàng và các dấu hiệu suy TMCDMT của vớ y khoa [20], [23], [24] nhưng những nghiên cứu về mức độ tuân thủ sử dụng vớ trên người bệnh này vẫn còn rất hạn chế. Ở nước ta hiện nay, các nghiên cứu tập trung chủ yếu về hiệu quả điều trị của thuốc, các phương pháp can thiệp ngoại khoa ${ }^{[1],[2],[15]}$ và chưa tìm thấy nghiên cứu cụ thể nào về mức độ tuân thủ sử dụng vớ y khoa trên người bệnh suy TMCDMT. Vì vậy, nghiên cứu mong muốn góp một phần vào việc đánh giá toàn diện hơn về hiệu quả điều trị của bệnh suy TMCDMT tại Việt Nam, đồng thời là cơ sở giúp đội ngũ Điều dưỡng hoàn thiện quy trình chăm sóc, tư vấn và hướng dẫn người bệnh suy TMCDMT nhằm giảm các triệu chứng và cải thiện chất lượng cuộc sống của người bệnh.

\section{Mục tiêu nghiên cứu:}

1. Xác định các đặc điểm dịch tễ học của nhóm nghiên cứu và đặc điểm lâm sàng ở người bệnh suy TMCDMT đến khám tại phòng khám Lồng Ngực - Mạch Máu Bệnh Viện Đại Học Y Dược TP. Hồ Chí Minh.

2. Xác định mức độ tuân thủ sử dụng vớ

\subsection{Phương pháp nghiên cứu:}

2.2.1. Thiết kế nghiên cứu: Cắt ngang mô tả

2.2.2. Xử lý và phân tích số liệu: Phần mềm thống kê Stata 13.0

\section{KẾT QUẢ NGHIÊN CÚU}

y khoa dựa trên khuyến cáo ở người bệnh suy TMCDMT.

3. Xác định mối liên quan giữa mức độ tuân thủ sử dụng vớ y khoa với các đặc điểm dịch tể học của nhóm nghiên cứu, đặc điểm lâm sàng ở người bệnh suy TMCDMT.

\section{II. ĐỐI TƯợNG VÀ PHƯƠNG PHÁP NGHIÊN CÚ'U}

\section{1. Đối tượng nghiên cứu}

Tất cả người bệnh được chẩn đoán suy TMCDMT tại Phòng khám Lồng ngực - Mạch máu Bệnh viện Đại học Y Dược TP. Hồ Chí Minh trong thời gian từ $05 / 2020$ đến $06 / 2020$.

\subsubsection{Tiêu chuẩn chọn mẫu}

- Nam hoặc nữ từ đủ 18 tuổi.

- Được chẩn đoán suy TMCDMT và có chỉ định mang vớ y khoa tại Phòng khám Lồng ngực Mạch máu Bệnh viện Đại học Y Dược TP. Hồ Chí Minh trong thời gian từ 05/2020 đến 06/2020.

- Tự nguyện tham gia vào nghiên cứu

\subsubsection{Tiêu chuẩn loại trù̀}

- Người bệnh đến khám lần đầu tiên.

- Người bệnh đã tham gia 1 lần trong đợt thu thập số liệu.

- Người bệnh đang mắc các bệnh cấp tính nặng: tai biến mạch máu não, nhồi máu cơ tim cấp, suy thận cấp, viêm phổi nặng ...

Người bệnh không hợp tác được: bất đồng ngôn ngữ, giảm thính lực, bệnh lý tâm thần... 
Bảng 1: Phân bố nhóm tuổi và giới tính của đối tượng nghiên cứu

\begin{tabular}{ccccc}
\hline \multirow{2}{*}{ Đặc tính } & \multicolumn{2}{c}{ Nam } & \multicolumn{2}{c}{ Nữ } \\
\cline { 2 - 5 } & Tần số & Tỉ lệ \% & Tần số & Tỉ lệ \% \\
\hline Nhóm tuổi & 1 & 11,1 & 5 & 6,3 \\
18-34 tuổi & 1 & 11,1 & 28 & 35,4 \\
35-50 tuổi & 5 & 55,6 & 33 & 41,8 \\
51-64 tuổi & 2 & 22,2 & 13 & 16,5 \\
$\geq 65$ tuổi & \multicolumn{2}{c}{$55,9 \pm 13,4$} & \multicolumn{2}{c}{$52,3 \pm 11,7$} \\
Tuổi trung bình & & & & \\
\hline
\end{tabular}

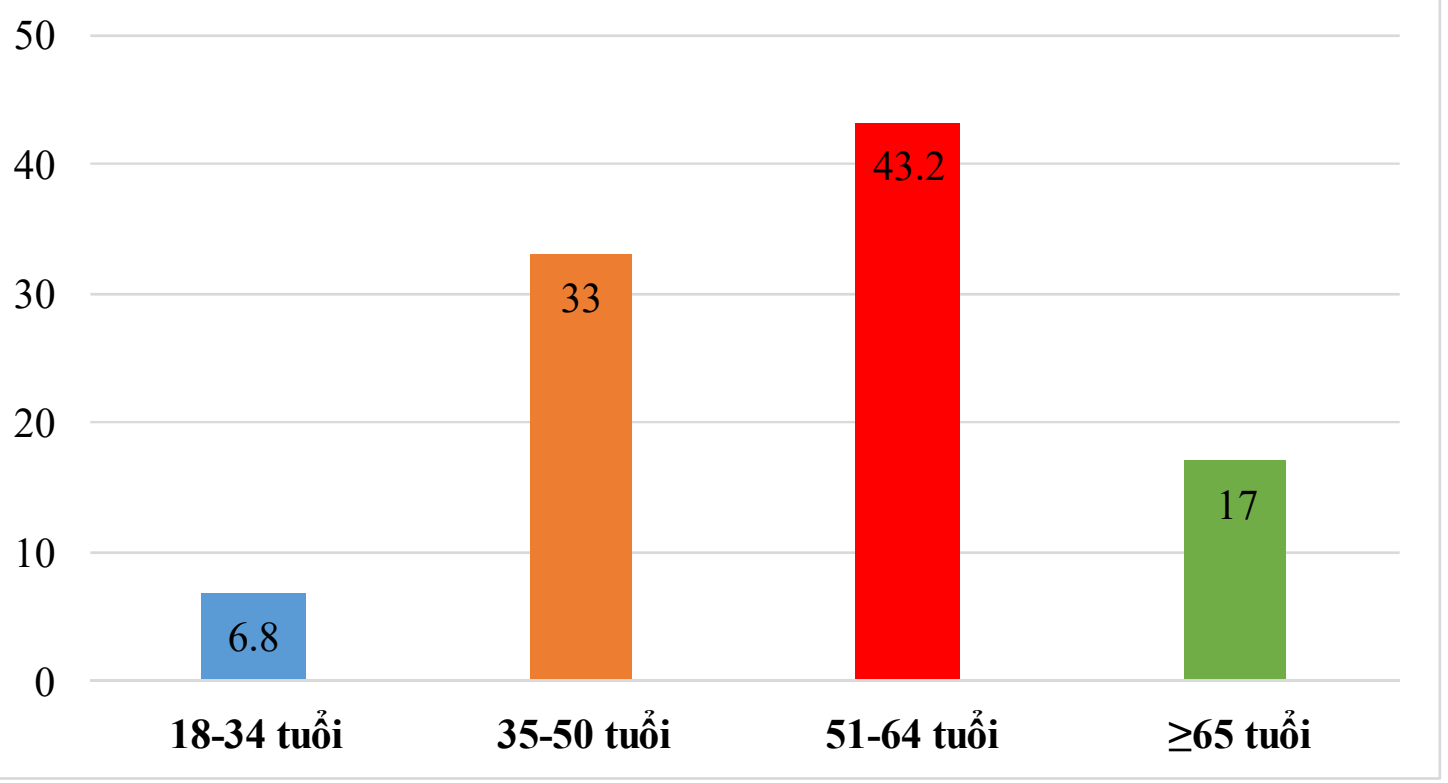

Biểu đồ 1: Phân bố nhóm tuổi của đối tượng nghiên cứu

Bảng 2: Phân bố nhóm chỉ số BMI, trình độ học vấn của đối tượng nghiên cứu

\begin{tabular}{lcc}
\multicolumn{1}{c}{ Đặc tính } & Tần số & Tỉ lệ \% \\
\hline Chỉ số BMI & & \\
Bình thường & 24 & 22,3 \\
Thừa cân & 22 & 25,0 \\
Béo phì & 42 & 47,7 \\
Chỉ số BMI trung bình & & $24,7 \pm 3,1$ \\
\hline
\end{tabular}




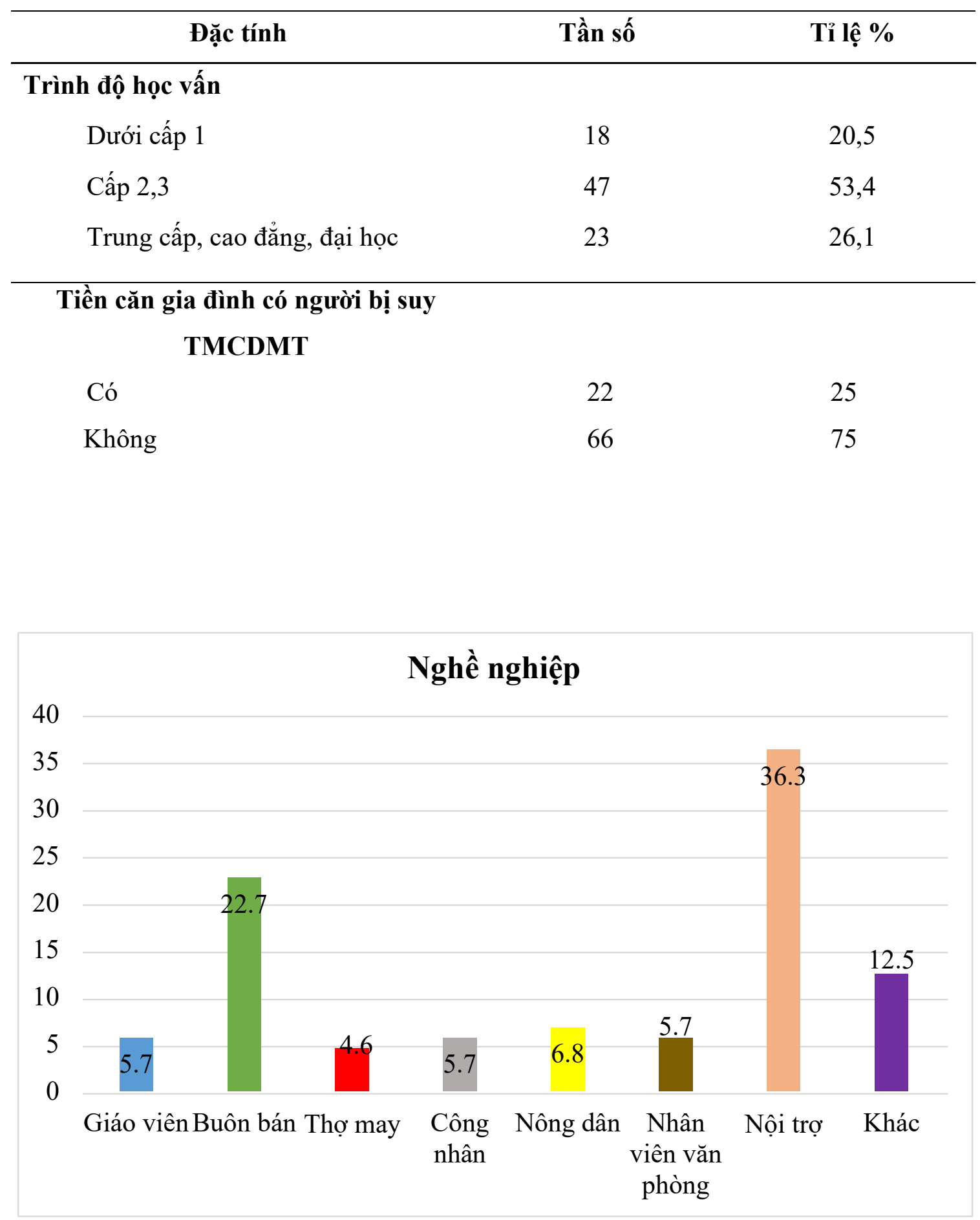

Biểu đồ 2: Phân bố nghề nghiệp của đối tượng nghiên cứu 
Bảng 3: Số lần mang thai và sử dụng thuốc tránh thai (đối với nữ giới)

\section{Đặc tính}

Tần số

Tỉ lệ \%

Số lần mang thai

$$
\begin{aligned}
& \leq 2 \text { lần } \\
& >2 \text { lần }
\end{aligned}
$$$$
54
$$$$
68,3
$$$$
25
$$$$
31,7
$$

Bảng 4: Đặc điểm lâm sàng của đối tượng nghiên cứu

\begin{tabular}{lcc}
\hline \multicolumn{1}{c}{ Đặc tính } & Tần số (n) & Tỉ lệ (\%) \\
\hline $\begin{array}{l}\text { Thò̀i gian từ lúc bệnh đến lúc đi } \\
\text { khám tại bệnh viện ĐHYD }\end{array}$ & 74 & \\
$<5$ năm & 12 & 84,1 \\
5-10 năm & 2 & 13,6 \\
>10 năm & & 2,3 \\
Số chi bị bệnh & 8 & 9,1 \\
Chân trái & 7 & 8,0 \\
Chân phải & 73 & 82,9 \\
Cả hai chân & $\mathbf{6 2}$ & $\mathbf{7 0 , 5}$ \\
\hline Bệnh kèm theo (có) & 24 & 38,7 \\
Tăng huyết áp/ tim mạch & 6 & 9,7 \\
Tiểu đường & 4 & 6,5 \\
Viêm khớp & 42 & 67,7 \\
Khác &
\end{tabular}

Các triệu chứng cụ thể

Nặng chân 38

43,2

Đau chân

Sưng, phù chân

Chuột rút

Nóng rát

Ngứa, tê bì, châm chích

17

19,3

\section{Phẫu thuật TM chi dưới}

Có

Không

62

70,5 
Bảng 5: Phân loại lâm sàng CEAP của đối tượng nghiên cứu

\begin{tabular}{lcc}
\hline \multicolumn{1}{c}{ Đặc tính } & Tần số (n) & Tỉ lệ (\%) \\
\hline Phân loại lâm sàng CEAP & 3 & 3,4 \\
C0 & 48 & 54,6 \\
C1 & 25 & 28,4 \\
C2 & 7 & 7,9 \\
C3 & 2 & 2,3 \\
C4 & 1 & 1,1 \\
C5 & 2 & 2,3 \\
C6 & & \\
Phân nhóm lâm sàng CEAP & 51 & 58,0 \\
Không phẫu thuật (C0;C1) & 13 & 14,8 \\
Không phẫu thuật (C2 - C6) & 20 & 22,7 \\
Có phẫu thuật (C2;C3) & 4 & 4,5 \\
Có phẫu thuật (C4;C5;C6) & & \\
\hline
\end{tabular}

Bảng 6: Tuân thủ sử dụng vớ y khoa của đối tượng nghiên cứu

\begin{tabular}{lcc}
\multicolumn{1}{c}{ Đặc tính } & Tần số (n) & Tỉ lệ (\%) \\
\hline $\begin{array}{l}\text { Tuân thủ sử dụng vớ y khoa (Mang vớ mối } \\
\text { ngày và mang } \geq \mathbf{8} \text { giờ/ngày) }\end{array}$ & \\
Có & 36 & 40,9 \\
Không & 52 & 59,1 \\
Cảm nhận khi sử dụng vớ y khoa & & \\
Khó mang & 21 & 23,9 \\
Khó chịu & 37 & 42,1 \\
Dễ chịu & 40 & 45,5 \\
Nóng, ngứa chân & 45 & 51,1 \\
Rất chặt & 71 & 80,7 \\
\hline
\end{tabular}


Bảng 7: Mối liên quan giữa mức độ tuân thủ sử dụng vớ y khoa với đặc điểm của đối tượng nghiên cứu

\begin{tabular}{|c|c|c|c|c|}
\hline \multirow{2}{*}{ Đặc tính } & \multicolumn{2}{|c|}{$\begin{array}{l}\text { Mức độ tuân thủ sử dụng } \\
\text { vớ y khoa }\end{array}$} & \multirow{2}{*}{$\begin{array}{c}\text { PR } \\
(\text { KTC 95\%) }\end{array}$} & \multirow{2}{*}{ Giá trị p } \\
\hline & Có & Không & & \\
\hline \multicolumn{5}{|l|}{ Trình độ học vấn } \\
\hline Dưới cấp 1 & $12(66,7)$ & $6(33,3)$ & 1 & \\
\hline Cấp 2,3 & $15(31,9)$ & $32(68,1)$ & $0,47(0,28-0,85)$ & $\mathbf{0 , 0 0 7}$ \\
\hline Trung cấp, cao & $9(39,1)$ & $14(60,9)$ & $0,59(0,32-1,08)$ & 0,086 \\
\hline \multicolumn{5}{|l|}{ đẳng, đại học } \\
\hline \multicolumn{5}{|l|}{ Phân nhóm lâm sàng } \\
\hline \multicolumn{5}{|l|}{ CEAP } \\
\hline Không PT (C0;C1) & $18(35,3)$ & $33(64,7)$ & $0,59(0,35-0,99)$ & 0,045 \\
\hline Không PT (C2 - C6) & $5(38,5)$ & $8(61,5)$ & $0,64(0,29-1,39)$ & 0,264 \\
\hline Có PT (C2;C3) & $12(60,0)$ & $8(40,0)$ & 1 & \\
\hline Có PT (C4;C5;C6) & $1(25,0)$ & $3(75,0)$ & $0,42(0,07-2,38)$ & 0,325 \\
\hline
\end{tabular}

\section{BÀN LUẬN \\ 4.1. Các đặc điểm dịch tể học của đối tượng nghiên cứu}

\subsection{1. Đặc điểm về tuổi}

Cao tuổi là yếu tố nguy cơ quan trọng của bệnh suy TMCDMT. Tuổi càng lớn nguy cơ mắc bệnh càng cao, do cơ bắp ở chân yếu hơn cùng với tổn thương thành TM làm tăng áp lực lên các TM chân. Theo Nguyễn Hoài Nam (2011) đánh giá trên 160 người bệnh suy TMCDMT tại bệnh viện Đại học Y Dược TP. Hồ Chí Minh cho thấy tuổi trung bình của người bệnh là 52,8 tuổi, dao động từ 23 đến 80 tuổi ${ }^{[3]}$. Nghiên cứu của tác giả Vũ Trí Thanh cùng cộng sự (2019) tuổi trung bình là 54 , dao động từ 30 đến 85 tuổi, có $76 \%$ độ tuổi từ 41 đến 70 tuổi ${ }^{[9]}$. Trong nghiên cứu của chúng tôi, tuổi trung bình của người bệnh là 55,9 ở nam và 52,3 ở nữ (Bảng 1 ), trong đó người bệnh có độ tuổi từ 51 đến 64 chiếm tỉ lệ cao nhất $43,2 \%$, kế đến là nhóm tuổi 35 đến 50 chiếm $33 \%$
(Biểu đồ 1 ). Như vậy, độ tuổi trong nghiên cứu của chúng tôi phù hợp với độ tuổi của người bệnh suy TMCDMT trong và ngoài nước, đồng thời phù hợp với dự đoán của các chuyên gia y tế về xu hướng trẻ hóa của bệnh.

\subsection{2. Đặc điểm về giới}

Suy TMCDMT là bệnh liên quan nhiều đến giới tính, trong đó giới nữ chiếm tỉ lệ cao hơn nam do chịu ảnh hưởng từ thuốc ngừa thai, nội tiết tố, số lần mang thai, giày cao gót, ...

Trong nghiên cứu của chúng tôi, đối tượng chủ yếu là nữ chiếm $89,8 \%$, nam là $10,2 \%$ (Bảng 1). Kết quả này cũng tương tự với nghiên cứu của tác giả Alvaro Ayala và cộng sự (2018) có đến $85,6 \%$ là nữ giới và $14,4 \%$ là nam giới ${ }^{[14]}$. nghiên cứu của Nguyễn Hoài Nam (2012) thấy rằng nữ giới chiếm $80 \%$, nam giới là $20 \%$, tỉ lệ nữ/nam là $4 / 1^{[4]}$. Như vậy, chúng tôi có thể khẳng định thêm rằng nữ giới có tỉ lệ mắc bệnh suy TMCDMT cao hơn so với nam giới. 


\subsubsection{Chỉ số khối cơ thể (BMI)}

Thừa cân/béo phì là yếu tố nguy cơ có liên quan mạnh đến bệnh suy TMCDMT, BMI trung bình trong nghiên cứu của chúng tôi là 24,7 , tỉ lệ béo phì chiếm $47,7 \%$ trong nhóm nghiên cứu (Bảng 2); tương tự nghiên cứu của Đặng Thị Minh Thu cùng cộng sự (2014) với BMI trung bình là 23,96 $\pm 3,31$ chiếm tỉ lệ $53,4 \%$ trong nhóm nghiên cứu ${ }^{[10]}$ và thấp hơn nghiên cứu cả tác giả Vuylsteke cùng cộng sự (2015) với BMI trung bình là $26,08 \pm 17,6^{[21]}$. Sự khác biệt về BMI trung bình giữa các nghiên cứu trong và ngoài nước có thể do sự khác biệt về thể trạng, thói quen ăn uống và sinh hoạt của người dân. Ở nước ta, trong những năm gần đây đã có sự phát triển về mọi mặt của đời sống kinh tế, trình độ dân trí và ý thức phòng bệnh ngày càng được nâng cao. Đặc biệt là phái nữ, họ rất sợ béo phì. Đa số người dân biết rằng thừa cân/béo phì là không tốt và dễ mắc các bệnh như tim mạch, tiểu đường,,..

\subsubsection{Trình độ học vấn}

Trong nghiên cứu của chúng tôi có $73,9 \%$ người bệnh có trình độ học vấn từ trung học phổ thông hoặc thấp hơn $(53,4 \%$ trình độ học vấn cấp $2,3$ và $20,5 \%$ là mù chữ/cấp 1$)$ (Bảng 2$)$. Tỉ lệ này tương đồng với nghiên cứu của Nguyễn Thị Thanh Thuần (2018) với $72,1 \%$ và cao hơn so với nghiên cứu của E.Soydan cùng cộng sự (2017) tại một bệnh viện ở Thổ Nhĩ Kỳ là $58,3 \%{ }^{[18]}$. Sự khác biệt này có thể do sự khác nhau về chính sách giáo dục và kinh tế-xã hội giữa các quốc gia, các vùng lãnh thổ.

\subsubsection{Nghề nghiệp}

Những đối tượng có nghề nghiệp đòi hỏi đứng lâu là yếu tố nguy cơ của bệnh suy TMCDMT đã được khẳng định trong rất nhiều nghiên cứu về dịch tễ học. Trong nghiên cứu của chúng tôi, tỉ lệ người bệnh có nghề nghiệp thuộc nhóm nguy cơ này là $80,7 \%(34,1 \%$ là giáo viên/buôn bán/công nhân, $10,3 \%$ là thợ may/NVVP, 36,3\% là nội trợ) (Biểu đồ 2). Theo nghiên cứu của tác giả Nguyễn Hoài Nam (2012) có đến $84,6 \%$ người bệnh thuộc nhóm nghề nghiệp liên quan đến đi, đứng nhiều ${ }^{[4]}$. Nghiên cứu của tác giả Đặng Thị Minh Thu cùng cộng sự (2014) thì tỉ lệ người bệnh có nghề nghiệp đứng, ngồi nhiều là $85,4 \%{ }^{[10]}$. Tuy nhiên, trong nghiên cứu của Lê Phước Nguyên và cộng sự (2015) cho thấy rằng không có mối liên quan giữa nghề nghiệp và giai đoạn của bệnh [5]. Như vậy, việc đứng lâu hay ngồi nhiều chỉ là yếu tố nguy cơ đối với bệnh suy TMCDMT chứ không làm tăng thêm độ nặng trên lâm sàng.

\subsubsection{Số lần mang thai}

Mang thai nhiều lần là yếu tố nguy cơ của suy TMCDMT. Nghiên cứu của chúng tôi tỉ lệ mang thai từ 1 đến 2 lần của nữ giới chiếm $68,3 \%$, trên 2 lần là $31,7 \%$ (Bảng 3); tương tự như nghiên cứu của Đặng Thị Minh Thu và cộng sự (2016) khảo sát trên 86 người bệnh suy TMCDMT là nữ thì số lần mang thai từ 1 đến 2 lần là $67,4 \%$, trên 2 lần là $32,6 \%{ }^{[10]}$ và cao hơn của Lê Phước Nguyên cùng cộng sự (2016) khảo sát trên 102 người bệnh là nữ, kết quả cho thấy tỉ lệ phụ nữ mang thai từ 1 đến 2 lần là $35,29 \%$, mang thai trên 2 lần là $49,02 \%{ }^{[6]}$. Hiện nay, hầu hết các gia đình trẻ đều dừng ở mức từ 1 đến 2 con. Điều này đã giải thích tỉ lệ sinh con trên 2 lần trong nghiên cứu của chúng tôi thấp. Chúng tôi tin rằng tỉ lệ này sẽ còn tiếp tục giảm do chính sách dân số và kế hoạch hóa gia đình ở nước ta vẫn còn phát huy tác dụng của nó.

\subsubsection{Thời gian phát hiện bệnh}

Trong nghiên cứu của chúng tôi, thời gian người bệnh phát hiện triệu chứng bệnh đến khi đi khám tại bệnh viện Đại Học Y Dược TP. Hồ Chí Minh dưới 5 năm là $84,1 \%$, từ 5 đến 10 năm là $13,6 \%$, trên 10 năm là $2,3 \%$ (Bảng 4 ). So với nghiên cứu của Nguyễn Hoài Nam (2012) cũng thực hiện tại bệnh viện Đại Học Y Dược TP. Hồ Chí Minh tỉ lệ người bệnh có thời gian mắc bệnh dưới 5 năm là $21,2 \%$, từ 5 đến 10 năm là $28,8 \%$, trên 10 năm là $50 \%{ }^{[4]}$. So sánh các kết quả trên 
cho thấy theo thời gian, người dân đã hiểu biết và quan tâm đáng kể về bệnh nên đi khám và điều trị bệnh sớm hơn.

\subsubsection{Yếu tố gia đình}

Tiền căn gia đình cũng là yếu tố nguy cơ cao đối với suy TMCDMT và bệnh $\mathrm{TM}$ khác đã được đề cập trong nhiều nghiên cứu. Trong nghiên cứu của chúng tôi, có $25 \%$ người bệnh có người thân trong gia đình cũng mắc bệnh suy TMCDMT (Bảng 3). Kết quả này tương đồng với nghiên cứu của Lê Phước Nguyên cùng cộng sự (2016) có $28,6 \%$ người bệnh có người thân trong gia đình cũng bị bệnh tương tự ${ }^{[6]}$. Tuy nhiên, theo Lê Thị Thu Trang cùng cộng sự (2016) có đến $61,3 \%$ người bệnh có người thân bị suy TMCDMT ${ }^{[11]}$. Hơn nữa, theo Lê Phước Nguyên cùng cộng sự (2015) nhận thấy không có sự tác động của yếu tố này lên giai đoạn bệnh, không làm tăng thêm mức độ nặng của bệnh ${ }^{[5]}$. Một vài khác biệt này chúng tôi có thể lý giải rằng người bệnh ít quan tâm đến đặc điểm về yếu tố gia đình vì họ cho rằng đây là bệnh không lây và tự phát của bản thân.

\subsubsection{Bệnh mãn tính kèm theo}

Độ tuổi trung bình trong nghiên cứu của chúng tôi là 55,9 ở nam và 52,3 ở nữ, đây là độ tuổi bắt đầu có nhiều bệnh tật đi kèm. Trong nghiên cứu của chúng tôi có đến $70,5 \%$ người bệnh trong nhóm nghiên cứu có bệnh mãn tính kèm theo, trong đó 38,7\% người bệnh có tăng huyết áp/tim mạch (Bảng 4); tỉ lệ này gần tương đồng với Nguyễn Thị Thanh Thuần (2018) là $23,5 \%$, thấp hơn nghiên cứu của tác giả Đặng Thị Minh Thu cùng cộng sự (2014) là 56,2\% [i10].

\subsubsection{Số chi bị bệnh}

Nghiên cứu của chúng tôi có $82,9 \%$ người bệnh bị suy TM cả 2 chân, bị chân trái chiếm $9,1 \%$ và với $8 \%$ bị chân phải (Bảng 4$)$. Tỉ lệ này tương đồng với nghiên cứu của tác giả Nguyễn Hoài Nam (2012) với 86\% người bệnh bị suy tĩnh mạch 2 chân, $14 \%$ chỉ bị 1 chân ${ }^{[4]}$.

\section{Triệu chứng lâm sàng}

Trong nghiên cứu của chúng tôi, người bệnh suy TMCDMT than phiền nhiều nhất là đau chân $54,6 \%$ và chuột rút về đêm $46,6 \%$, tiếp đến là nặng chân $43,2 \%$, sưng phù $43,2 \%$, ngứa/tê bì/châm chít $19,3 \%$ và sau cùng là nóng rát chân $4,6 \%$; có $75 \%$ các đối tượng có từ 2 triệu chứng trở xuống và $25 \%$ có trên 2 triệu chứng; có $29,5 \%$ người bệnh có can thiệp phẫu thuật $\mathrm{TM}$ chi dưới (Bảng 4). Kết quả này tương đồng nghiên cứu của Nguyễn Bình Triệu cùng cộng sự với 90,3\% người bệnh có nặng/đau chân, 33\% bị chuột rút, 32\% bị sưng phù ${ }^{[12]}$. Đây cũng là những triệu chứng cơ năng điển hình của bệnh suy TMCDMT.

\subsubsection{Phân loại lâm sàng CEAP}

Phân loại CEAP được xem là phân loại lý tưởng nhất, vì nó xem ét đến tất cả những khía cạnh chính của bệnh suy TMCDMT. Trong nghiên cứu của chúng tôi, người bệnh cũng được xếp loại theo CEAP nhưng không đánh giá đầy đủ các mặt, chúng tôi chỉ chọn tiêu chí lâm sàng (C). Kết quả tìm thấy người bệnh ở độ $\mathrm{C} 1$ là nhiều nhất $54,6 \%$; độ $\mathrm{C} 2$ với $28,4 \%$; ở độ $\mathrm{C} 0$ với $3,4 \%$; độ $\mathrm{C} 4$ và độ $\mathrm{C} 6$ với $2,3 \%$; chiếm tỉ lệ thấp nhất là các đối tượng ở độ $\mathrm{C} 5$ với $1,1 \%$. Phân nhóm lâm sàng $\mathrm{CEAP}(\mathrm{C} 0 ; \mathrm{C} 1)$ ở nhóm không phẫu thuật chiếm $58 \%$ và nhóm không phẫu thuật (C2 - C6) chiếm 14,8\%. ở nhóm có phẫu thuật $(\mathrm{C} 2 ; \mathrm{C} 3)$ chiếm $22,7 \%$ và nhóm $(\mathrm{C} 4 ; \mathrm{C} 5 ; \mathrm{C} 6)$ chiếm 4,5\% (Bảng 5). Trong nghiên cứu của Daciana Elena Branisteanu và cộng sự (2018) độ lâm sàng $\mathrm{CEAP}$ từ $\mathrm{C} 0$ đến C6 lần lượt là $5,49 \%$, $21,02 \%, 28 \%, 31,85 \%, 11,19 \%, 2,17 \%$ và $0,26 \%$ [17] và theo Nguyễn Hoài Nam (2012) người bệnh ở độ $\mathrm{C} 2$ là $69,2 \%$; C3 là $15,4 \%$; C4 là $9,6 \%$; $\mathrm{C} 5$ là $5,8 \%$ không có người bệnh thuộc nhóm $\mathrm{C} 0$ và $\mathrm{C6}{ }^{[4]}$. Từ kết quả trên cho thấy, người bệnh ở độ $\mathrm{C} 0$ và $\mathrm{C} 1$ trong nghiên cứu của chúng tôi cao hơn các nghiên cứu còn lại. Điều này cho thấy, người bệnh đã có hiểu biết và có thói quen đi khám khi bệnh còn ở giai đoạn sớm. 


\subsection{Mức độ tuân thủ sử dụng vớ y khoa}

\subsubsection{Tuân thủ sử dụng vớ y khoa:}

Tuân thủ sử dụng vớ $\mathrm{y}$ khoa là: Người bệnh mang vớ $\mathrm{y}$ khoa mỗi ngày, mang vào khoảng thời gian đầu tiên trong ngày khi bước chân xuống giường cho đến khi đi ngủ tối và tổng thời gian mang vớ trong ngày tối thiểu là 8 giờ [13], [16]

Vớ y khoa được khuyến cáo sử dụng cho người bệnh suy TMCDMT với mục đích làm giảm áp lực trong tĩnh mạch khi đứng lâu và đi lại nhiều trong ngày. Trong nghiên cứu của chúng tôi, chỉ có 40,9\% người bệnh suy TMCDMT tuân thủ sử dụng vớ $\mathrm{y}$ khoa, 59,1\% người bệnh còn lại mang không tuân thủ (Bảng 6 ). Tỉ lệ này cao hơn so với nghiên cứu của Alvaro Ayala và cộng sự (2018) trên 889 người bệnh suy TMCDMT cho thấy chỉ có $31,4 \%$ người bệnh tuân thủ mang mỗi ngày, 28,3\% mang không liên tục, 8,5\% không mang ${ }^{[14]}$ và theo nghiên cứu của D.Rastel (2014) cho thấy chỉ có $29 \%$ người bệnh tuân thủ mang vớ trong đó $10,4 \%$ mang vớ hàng ngày, $32,6 \%$ không mang ${ }^{[16]}$.

\subsubsection{Nguyên nhân ảnh hưởng đến mức} độ tuân thủ sử dụng vớ y khoa

Chúng tôi thấy rằng, người bệnh than phiền nhiều nhất khi sử dụng vớ $\mathrm{y}$ khoa là bị bó chặt $(80,7 \%)$, nóng/ngứa chân $(51,5 \%)$, khó chịu (42\%), khó mang (23,9\%) (Bảng 6). Trong nghiên cứu của Alvaro Ayala cùng cộng sự (2018) lý do người bệnh không tuân thủ vì khó chịu $(49,4 \%)$, khó mang $(34,6 \%)$ và nóng/ngứa chân $(21,6 \%)^{[14]}$.

\subsubsection{Mối liên quan giữa mức độ tuân thủ} sử dụng vớ y khoa với một số đặc điểm của đối tượng nghiên cúu

\subsubsection{Trình độ học vấn}

Nhóm người bệnh có trình độ học vấn từ cấp 1 trở xuống có sự tuân thủ cao hơn $(66,7 \%)$ so với nhóm người bệnh có trình độ học vấn cấp 2/cấp $3(31,9 \%)$ và trung cấp/cao đẳng/đại học $(39,1 \%)(p=0,007)$ (Bảng 7). Theo Şinasi Manduz cùng cộng sự (2018) cho thấy có đến 64,6\% người bệnh có trình độ học vấn từ cấp 1 trở xuống; tuy nhiên, có đến 54,4\% người bệnh cho rằng vớ $\mathrm{y}$ khoa là một phần của điều trị và tuân thủ đúng, 35,3\% không biết, 10,1\% không có ý kiến ${ }^{[25]}$. Sự tương đồng này có thể lý giải rằng nhóm người bệnh có trình độ học vấn thấp hầu hết là lao động chân tay, làm những công việc nặng, đi đứng nhiều trong ngày nên thấy được sự cải thiện rõ rệt các triệu chứng của suy $\mathrm{TM}$; hơn nữa họ có được rất ít thông tin và sợ khi thấy các biến chứng nguy hiểm của bệnh nên tuân thủ tốt hơn và tích cực hơn.

\subsubsection{Phân loại lâm sàng CEAP}

Kết quả nghiên cứu của chúng tôi ghi nhận có sự khác biệt về sự tuân thủ sử dụng vớ y khoa giữa các nhóm theo phân loại lâm sàng CEAP, cụ thể nhóm lâm sàng $\mathrm{C} 0-\mathrm{C} 1$ không có chỉ định phẫu thuật có tỉ lệ tuân thủ sử dụng vớ $\mathrm{y}$ khoa bằng 0,59 lần so với nhóm lâm sàng $\mathrm{C} 2-\mathrm{C} 3$ có can thiệp phẫu thuật, sự khác biệt có ý nghĩa thống kê với $\mathrm{p}=0,045$ (Bảng 7). Marco Antonio Ayala-Garcia cùng cộng sự (2019) báo cáo rằng mức độ tuân thủ sử dụng vớ y khoa tăng dần theo phân độ loại sàng $\mathrm{CEAP}$; cụ thể ở độ $\mathrm{C} 1$ mức độ tuân thủ là $22,8 \%, \mathrm{C} 2$ là $34,3 \%, \mathrm{C} 3$ là $44,4 \%, \mathrm{C} 5$ và $\mathrm{C} 6$ đều là $50 \%{ }^{[22]}$. Theo các chuyên gia, người bệnh suy TMCDMT từ mức độ $\mathrm{C} 2$ trở đi thường sẽ có chỉ định can thiệp ngoại khoa để loại bỏ dòng trào ngược và cải thiện triệu chứng lâm sàng. Do đó, khi người bệnh ở giai đoạn từ $\mathrm{C} 2$ đến C6 họ đã được chỉ định can thiệp phẫu thuật và thấy được các triệu chứng cơ năng, thực thể rõ ràng, trầm trọng và có thể đã xuất hiện biến chứng. Đây cũng là nguyên nhân tuân thủ sử dụng vớ y khoa của người bệnh ở các giai đoạn này cao hơn nhằm ngăn ngừa diễn tiến nặng hơn của bệnh.

\section{KẾT LUẬN}

Người bệnh suy TMCDMT có trình độ học vấn từ cấp 1 trở xuống có mức độ tuân thủ sử dụng vớ y khoa cao hơn các nhóm còn lại. 
Nhóm phân loại lâm sàng theo CEAP có can thiệp phẫu thuật thì mức độ tuân thủ sử dụng vớ y khoa cao hơn nhóm không phẫu thuật.

Mức độ tuân thủ sử dụng vớ y khoa ở người bệnh suy TMCDMT còn thấp. Nguyên nhân gây trở ngại cho việc tuân thủ sử dụng vớ y khoa trong nhóm nghiên cứu: bó chặt, nóng/ngứa chân, khó chịu, khó mang.

\section{TÀI LIẸU THAM KHẢO}

1. Hồ Khánh Đức, Cao Văn Thịnh, Nguyễn Công Minh, Phan Thanh Hải, Văn Tần (2014) "Điều trị suy tĩnh mạch nông chi dưới bằng phương pháp laser nội tĩnh mạch (kết quả sau 2 năm theo dõi)". Tạp chí Y hoc Tp. Hồ Chí Minh, 1, 418-423.

2. Nguyễn Minh Đức, Bùi Văn Dũng, Đặng Thị Việt Hà, Vũ Trung Anh, Phạm Thị Thanh Huyền, Phạm Thắng (2017) "Đánh giá hiệu quả điều trị suy tĩnh mạch hiển bé mạn tính bằng phương pháp gây xơ tạo bọt". Tạp chí nghiên cúu y hoc., 2, 88-94.

3. Nguyễn Hoài Nam (2011) "Nghiên cứu cài tiến kỹ thuật trong điều trị ngoại khoa dãn tĩnh mạch nông chi dưới mạn tính.". Tạp chí Y hoc Tp. Hồ Chí Minh, 1, 460-463.

4. Nguyễn Hoài Nam (2012) "Nghiên cứu biểu hiện dịch tể học lâm sàng của bệnh suy tĩnh mạch chi dưới mạn tính.". Tạp chí Y hoc Tp. Hồ Chi Minh, 1, 202-205.

5. Lê Phước Nguyên, Lê Hoàng Hạnh, Tạ Văn Trầm, Lê Nữ Hòa Hiệp (2015) "Sự liên quan giữa các yếu tố nguy cơ và giai đoạn lâm sàng bệnh suy tĩnh mạch chi dưới mạn tính". Tạp chí $Y$ hoc Tp. Hồ Chí Minh, 5, 122-128.

6. Lê Phước Nguyên, Tạ Văn Trầm, Lê Nữ Hòa Hiệp (2016) "Yếu tố nguy cơ bệnh suy tĩnh mạch mạn tính chi dưới.". Tạp chí Y hoc Tp. Hồ Chí Minh, 2, 521-526.

7. Nguyễn Lương Quang (2018) "Suy tĩnh mạch mạn tính chi dưới: Cập nhật chẩn đoán và điều trị". http://bvdkquangnam.vn, 1798, 1-7.
8. Nguyễn Trường Sơn (2015) "Bệnh suy giãn tĩnh mạch chi dưới". https://moh.gov.vn, 1-3.

9. Vũ Trí Thanh, Đào Duy Phương (2019) "Đánh giá hiệu quả lâm sàng theo thang điểm VDS trong điều trị suy tĩnh mạch chi dưới bằng laser nội mạch tại Bệnh viện Đại học Y dược TP. Hồ Chí Minh.". Tạp chí Y học Tp. Hồ Chí Minh, 4, 40-45.

10. Đặng Thị Minh Thu, Nguyễn Anh Vũ (2014) "Đặc điểm lâm sàng và một số yếu tố nguy cơ của suy tĩnh mạch mạn tính chi dưới.". Tạp chí tim mạch học Việt Nam, 66, 175-188.

11. Lê Thị Thu Trang, Phạm Thắng, Nguyễn Trung Anh (2016) "Nghiên cứu hiệu quả biện pháp gây xơ bọt trong điều trị các bệnh nhân suy tĩnh mạch chi dưới mạn tính". Tạp chí tim mạch học Việt Nam, 75+76, 131-136.

12. Nguyễn Bình Triệu, Nguyễn Thu Hà, Vũ Minh Phúc, Trần Đức Hùng (2018) "Kết quả chăm sóc, tư vấn, hướng dẫn, luyện tập bệnh nhân suy tĩnh mạch mông chi dưới được điều trị bằng laser nội mạch tại bệnh viện Quân Y 103.". Khoa học Điều duõng, 1, 105-109.

13. A Stansal, I Lazareth, U Michon Pasturel, P Ghaffari, V Boursier, S Bonhomme, et al. (2013) "Compression Therapy in 100 Consecutive Patients With Venous Leg Ulcers.". Journal des Maldies Vasculaires, 38, 252-258.

14. Alvaro Ayala, Jose D Guerra, Jorge H Ulloa, Lowell Kabnick (2018) "Compliance with compression therapy in primary chronic venous disease: Results from a tropical country.". Phlebology, 0(0), 1-6.

15. C Wittens, A H Davies, N Bækgaard, R Broholm (2015) "Editor's Choice e Management of Chronic Venous Disease". Eur J Vasc Endovasc Surg, 49, 678-737.

16. D Rastel (2014) "Treatment by medical compression stockings among 144 consecutive patients with non-complicated primary varicose veins: Results on compliance.". Journal des Maldies Vasculaires, 39, 389-393. 
17. Daciana Elena Branisteanu, Toni Feodor, Sorin Baila, Iuliana Alma Mitea, Oana Vittos (2018) "Impact of chronic venous disease on quality of life: Results of vein alarm study". Experimental and Therapeutic Medicine, 17, 1091-1096.

18. Ebru Soydan, Emel Yılmaz, Hakan Baydur (2017) "Effect of socio-demographic characteristics and clinical findings on the quality of life of patients with chronic venous insufficiency". Vascular, 25 (4), 382-389.

19. Fedor Lurie, Brajesh K Lal, Pier Luigi Antignani, John Blebea, Ruth Bush, Joseph Caprini, et al. (2019) "Compression therapy after invasive treatment of superficial veins of the lower extremities: Clinical practice guidelines of the American Venous Forum, Society for Vascular Surgery, American College of Phlebology, Society for Vascular Medicine, and International Union of Phlebology". J Vasc Surg Venous Lymphat Disord, 7 (1), 17-28.

20. J L Cataldo, J M Pereira de Godoy, N de Barros Jr (2012) "The use of compression stockings for venous disorders in Brazil". Phlebology, 27, 33-37.

21. 1M E Vuylstekea, S Thomisb, G Guillaumec, M L Modliszewskid, N WeideseI, Staelens (2015) "Epidemiological Study on
Chronic Venous Disease in Belgium and Luxembourg: Prevalence, Risk Factors, and Symptomatology". European Society for Vascular Surgery, 49, 432-439.

22. Marco Antonio Ayala-Garc, Jorge Reyes Sanche'z, Norberto Munoz Montes, Eduardo Guant-Guerra (2019) "Frequency of use of elastic compression stockings in patients with chronic venous disease of the lower extremities.". Phlebology, 1-5.

23. Owayed Al Shammeri, Nourah AlHamdan, Bushra Al-hothaly, Farid Midhet, Mahboob Hussain, Abdulrahman Al-Mohaimeed (2014) "Chronic Venous Insufficiency: prevalence and effect of compression stockings". International Journal of Health Sciences, 8, 232-236.

24. Ryota Sugisawa, Naoki Unno, Takaaki Saito, Naoto Yamamoto (2016) "Effects of Compression Stockings on Elevation of Leg Lymph Pumping Pressure and Improvement of Quality of Life in Healthy Female Volunteers: A Randomized Controlled Trial". Lymphat Res Biol, 14 (2), 95-103.

25. Şinasi Manduz, Fatih Ada, Yusuf Ada (2018) "The level of awareness and the attitude of patients recommended for use of compression stockings in Turkish society, and investigation of the factors affecting their use.". Patient Preference and Adherence, 12, 399-407. 